\title{
Sudden death of 7th Duke of Marlborough
}

Sir,

It seems to be widely believed that the nineteenth century physicians were, rather surprisingly, unfamiliar with coronary artery disease. In this context, your readers may be interested in a letter which recently came to light, in which Sir William Gull writes to William T. Gairdner, then Professor of Medicine in Glasgow, to give him the facts relating to the sudden death of the 61-year-old Duke of Marlborough.

July 14, 1883.

71, Brook Street, Grosvenor Square, W.

\section{Dear Dr. Gairdner,}

The circumstances under which the Duke of Marlborough died were rare, though not peculiar. During life, the heart was from time to time examined, but there was nothing that could be noted abnormal either in the rhythm or sounds.

There had never been any symptoms of angina.
Postmortem. The coronary arteries of the heart were found atheromatous and calcareous, with obliteration of some branches. Cardiac muscle fibroid in corresponding points.

These facts I believe are the main ones of the case, so far as the mode of death went;-which must have been quite sudden.

With kind regards, I am,

Yours very truly, W'illiam W. Gull

An additional note headed 'Information from a daughter', and dated July 8, 1883, states:

'Neither Gull nor Acland had the least suspicon of heart disease. Had no symptoms of it-was strong on the moors last season. Talked with his son Randolph on the Egyptian political affair till 11.15.

'Had undressed, wound up his watch, lit his wife's nightlight in next room, shut the door and was found on the floor in his dressing gown.

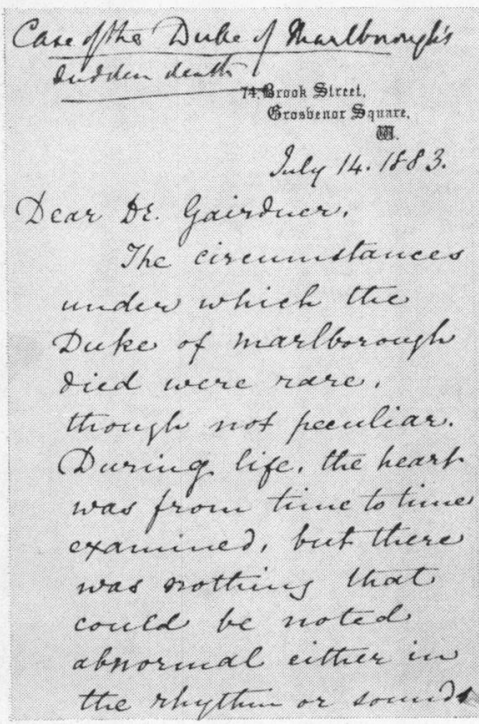

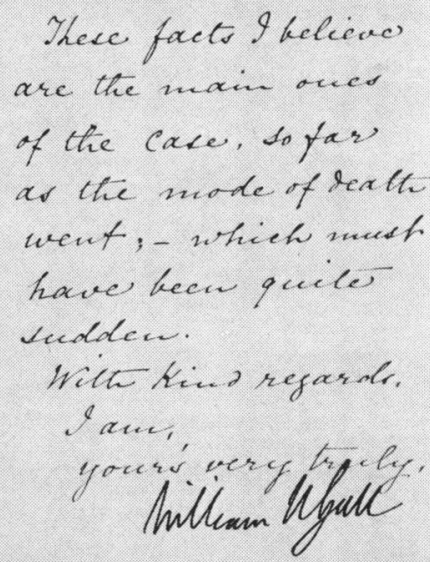


'Ossification of the valves found after death.'

Gairdner was, like Gull, a cardiologist and the letter implies that cardiac infarction was in fact well accepted, at least among cardiologists of the day, as a cause of sudden death, which might or might not be preceded by anginal symptoms.

The reference to Egyptian affairs may interest students of the history of the times, who will recall that in the preceding year (1882) British troops had landed in Egypt and, after the battle of Tel-elKebir, had restored the Khedive who had been deposed in a coup d'état by Arabi Pasha. Lord
Randolph Churchill (Winston Churchill's father) had become the leader of a group in the House of Commons which fiercely opposed the Gladstone government's Egyptian policy and supported the Arabists. One of Arabi's officers was summarily executed in defiance of an assurance by the Government to examine his case, and it was no doubt this event which Lord Randolph was discussing with his father so shortly before the latter's death.

Douglas Gairdner, 17 Rutherford Road, Cambridge CB2 2HH 